\title{
NEM SEMPRE AS COISAS FORAM ASSIM: OU DOS (DES)ENCANTAMENTOS DO CAMPO POLÍTICO E RELIGIOSO FRENTE AS ELEIÇÕES DE 2006
}

\author{
Mauro Meirelles ${ }^{*}$
}

Resumo: O presente artigo busca explorar algumas mudanças ocorridas no cenário eleitoral de Porto Alegre a partir da análise do período eleitoral e das estratégias de campanha utilizada pelos presidenciáveis. Neste sentido, a partir do conjunto de representações existentes entre as maisdiferentes comunidades ou gruposreligiosos acerca do campopolíticotenta-seexaminar os mecanismos discursivos utilizados pelos candidatos a presidência com vistas à conquista deste cargo eletivo. Para isto, nos utilizamos de uma aproximação das categorias de análise utilizadas por Mauss para o campo da magia com os papéis desempenhados pelos candidatos a Presidência dentro campo político. Sobretudo, neste estudo, tentamos testar o alcance explicativo do que denominamos de "Tese do Xamanismo" no que se refere ao uso dos efeitos perlocutórios do discurso utilizado pelos dois principais candidatos.

Palavras-chave: Eleições, Política, Religião, Efeitos perlocutórios do discurso.

\section{OLHANDO PARA TRÁS: AS ELEIÇÕES DE 2002 E 2004}

Os anos passam e as coisas mudam, parece-nos muitas vezes que não, mas pequenos detalhes que podem passar despercebidos ao olhar desatento trazem consigo profundas mudanças de comportamento. Se em nossa vida privada isso acontece com freqüência, na coisa pública, isso não seria diferente. O que se faz necessário é que estejamos atentos aos sinais que nos são apresentados diariamente em todos os lugares por onde passamos. Muitos são os aspectos com os quais eu, poderia me ocupar nesse texto, pois a análise do cotidiano das grandes cidades é um "prato farto" para a An tropologia em suas mais diferentes especialidades e vertentes teóricas.

Debruçar-se sobre uma etnografia do cotidiano das grandes metrópoles não é tarefa fácil e exige do antropólogo clareza e precisão no desvendar de seu objeto. Muitas vezes, podemos passar despercebidos (Geertz, 1978) até que algum fato nos traz para dentro da cena. Outras vezes, participamos ativamente do processo (Velho, 1978; Da Matta, 1978), contudo, é sempre importante que estejamos preparados para o imponderado.

* Licenciado em Ciências Sociais (UFRGS), Mestre em Educação (PPGEDU/UFRGS) e Professor Substituto do Departamento de Ensino e Currículo da Universidade Federal do Rio Grande do Sul (DEC/FACED/UFRGS). 
Se nas eleições passadas ao andarmos pelas ruas de Porto Alegre se fazia presente o momento político através de santinhos, panfletos, banners nas casas e edifícios, bandeiras empunhadas, adesivos nos carros e nas roupas, discussões acaloradas nos bares, filas, paradas de ônibus, etc. no que Barreira (1998) denomina de momento da política, hoje, com a nova lei eleitoral, muitos desses recursos midiáticos utilizados pelos candidatos fazem parte do passado em Porto Alegre.

Assim, se em eleições anteriores Oro (2004) aponta para a existência de uma pluralidade de candidaturas religiosas e para um insucesso de algumas candidaturas religiosas, enquanto Meirelles \& Di Franco (2004) nos remetem a uma bipolaridade discursiva entre os candidatos e, ainda, Guigou (2004), entre outros, apontam a emergência de um cenário político caracterizado por uma plasticidade manifesta nos materiais de campanha, jingles eleitorais, etc. tão comuns no cotidiano das grandes metrópoles durante o período eleitoral, temos que, hoje, as coisas mudaram e o que observamos é um cenário de crescente apatia política.

\section{OBSERVANDO O PRESENTE: AS ELEIÇÕES DE 2006}

No dia 1 de outubro de 2006 quando saímos de casa para votar observamos (ou acabamos por constatar) que esse período eleitoral é algo que destoa completamente daqueles que vivemos em eleições passadas em Porto Alegre. O cenário é bastante diferente, a boca de urna e a distribuiçáo farta de santinhos e colinhas próximos às sessões eleitorais não existem, em seu lugar, uma campanha silenciosa nos veículos agora adesivados com material publicitário dos mais diferentes candidatos. A chuva de papel dá lugar aos adesivos estáticos nos carros que passam a fazer parte da paisagem que circunda as sessões eleitorais. Nas sessões de votação, o clima é de continuidade e não se observa muitas discussões ou disputas pelos votos de última hora. Mas o que aconteceu com aquele eleitor que discutia, debatia com o amigo na fila da sessão sobre qual seria o melhor candidato? Cadê o adesivo do seu candidato ou partido que este eleitor levava orgulhosamente em seu peito nas outras eleições?

Uma resposta pontual a este questionamento não é tarefa fácil, mas podemos, com base em trabalhos desenvolvidos por outros pesquisadores que se ocupam no fenômeno eleitoral, tentar tecer algumas possibilidades que nos permitem explorar a questão de forma mais contundente. Dentre os muitos debates que cercaram o momento pré-eleitoral, três deles nos chamam a atenção.

O primeiro deles reside na tese de uma democracia cansada levantada pelo professor Newton Bignotto, da Universidade Federal de Minas Gerais, em entrevista concedida ao jornal Zero Hora do dia 26 de agosto de 2006. Segundo ele, as constantes crises que passamos nos últimos anos envolvendo figuras proeminentes do campo político levaram a que se produzisse um clima de desinteresse e desânimo em relação à agenda política brasileira.Tal constatação, também, assenta-se no que Baquero (1999) denomina de um crescente sentimento de apatia e descrédito dos cidadãos com relação à coisa pública, manifesta numa sensação de incerteza e temor em relação ao futuro. Ainda nesta direção como exposto por Meirelles \& Di Franco (2004) temos que a crença no "momento mágico do

Debates do NER, Porto Alegre, ANo 7, N. 10, P. 51-64, jul./Dez. 2006 
voto", como uma forma de resolução dos problemas sociais, já não faz mais sentido, dado que, no pleito de 2006, se faz muito mais presente uma sensação de apatia e descaso com relação aos atores da cena política do que a esperança de mudança.

O segundo refere-se novamente a esse momento de apatia que vive a democracia brasileira, enfocando que tal cenário se mostra bastante perigoso para a "saúde da democracia brasileira" na medida em que, devido ao desin ter esse que produz no cidadão, como coloca Baquero (1999), acaba por gerar u ma "eleição morna", que não dá espaço a debates acalorados de propostas e que, por conseqüência, daria margem à reeleição de políticos envolvidos em esquemas ilícitos e/ou o surgimento de candidatos salvadores com propostas milagrosas. Neste sentido, se cruzarmos os nomes dos candidatos eleitos no primeiro turno para as assembléias estaduais e as câmaras federais neste pleito eleitoral que se encerrou no dia 1 de outubro de 2006 com o nome dos políticos envolvidos em esquemas de corrupção e CPIs teremos a real dimensão do exposto nesta tese que defende o debate acalorado entre as propostas políticas apresentadas pelos candidatos.

O terceiro reside na crença das pessoas no mito da efervescência que deve sempre cercar o momento eleitoral, tese defendida por André Marenco dos Santos. Segundo esta perspectiva, seria comum à maioria das pessoas o fato de que as eleiçôes são sempre um momento de apoteose política, o que é raro, até mesmo, nas melhores democracias. Para André Marenco dos Santos, à medida que o processo eleitoral se torna rotineiro, há um tendência à indiferença do cidadão com relação ao mesmo.

Seria, então, essa a resposta para os dois questionamentos que ora apresentamos? A resposta é não, visto que, todos esses autores se pautam em dimensões pontuais do processo político, qual seja, o momento eleitoral apenas. Todavia, se descentrarmos nosso olhar do processo eleitoral em si e passarmos nosso foco para o entendimento da sociedade como um todo, somos obrigados a aceitar a tese de que as eleições são apenas um momento onde questôes vividas cotidianamente, pela maioria dos cidadãos, são colocadas em debate em função de interesses pessoais e propostas apresentadas por líderes políticos. Outrossim, seria a partir deste debate de propostas e questóes que envolvem o cotidiano de grande parte do cidadãos que os candidatos buscariam a conquista do voto do eleitor e o direito de ser o líder legítimo de uma nação.Desta forma, somos remetidos diretamente às obras de autores clássicos da ciência política, tais como: Hobbes (2004), Locke (1998) e Rousseau (1991) e a forma como estes concebem o processo de representação política. Para estes autores o processo de representação se daria pela cessão do direito de decidir em favor de um soberano. Via de regra, à exceção de Hobbes, todos têm como pressuposto a via democrática - em maior ou men or grau - como a melhor forma de escolha de seus líderes. Também, não podemos esquecer de autores contemporâneos como Robert Dahl (1987) e a idéia de democracia poliárquica que permite ao cidadão intervir na política por muitos caminhos que escapam às estruturas rígidas dos partidos políticos. Da mesma forma, encontramos em Foucault (1985) um estudo contundente das formas como esse poder é diluído (ou disperso) nas mais diversas instâncias e em que medida, esse micro-poder torna-se a base de sistemas de representação fortemente consolidados.

Em todos esses autores, dadas às peculiaridades do momento em que conceberam as suas obrase, à exceçáo de Michel Foucault, que se ocupa muito mais das dinâmicas do poder do que

Debates do NER, Porto Alegre, ANO 7, N. 10, P. 51-64, JUl./DEZ. 2006 
de um modelo de estado em espećfico, temos presente a idéia de representação como lócus privilegiado para o entendimento do campo político. É, então, na idéia de representação e percepção do campo político tida pelas comunidades religiosas que nos centraremos na busca de algumas respostas para nossos questionamentos sobre o atual momento político brasileiro.

\section{AS REPRESENTAÇÕES DAS COMUNIDADES RELIGIOSAS SOBRE O CAMPO POLÍTICO NO CENÁRIO PRÉ-ELEITORAL}

Antes de adentrarmos na noção de representação propriamente para o entendimento do atual momento político, é preciso que exploremos dois conceitos que nos ajudarão no entendimento desta questão, são eles: a noção de campo de Pierre Bourdieu e a noção de comunidade de Zygmunt Bauman.

\section{A NoÇão de CAMPo EM Pierre Bourdieu}

No que se refere à idéia de campo e, em especial, fazendo referência ao campo político e religioso temos que - como nos alerta Bourdieu (2003) a partir dos escritos de Marx - a "imigração de id éias" ou a "reapropriação discursiva de discursos ext er nos" à um dado campo ou conjunto de pessoas que compartilham um mesmo espaço de vivência objetiva e interlocução não ocorre sem danos. Embora, nos sejam óbvios os problemas desta imigração ou transposição de idéias, formas de perceber e ver o mundo, o que se observa, é que ela ocorre e com uma freqüência bem maior do que imaginamos.

É inegável que existem disputas de poder por toda a parte e que esse poder, ora se encontraconcentrado nasmãos de uns(Hobbes, 2004; Rousseau, 1991; Bourdieu, 2003), ora, disperso entreos sujeitos que compōem um determinado grupo, sociedade e/ou comunidade (Foucault, 1985; Bauman, 2003). E notório, também, que muitas vezes não se queira reconhecê-lo mesmo que estenos salte aos olhos ou, comocoloca Bourdieu(2003, p. 7), acabamos por dissolvê-lo "em uma espécie de círculo cujo centro está em toda a parte e em parte alguma".

Diante do exposto, faz-se necessário que, minimamente, sejamos capazes de saber descobri-lo, de saber onde este se faz menos presente e onde ele é completamente ignorado. Outrossim, com base na acepção hegeliana, temos então que é pela sua negação que se constitui o seu reconhecimento. E, é, essa influência invisível (ou tornada não-visível), por aqueles que sofrem seu efeito, que Bourdieu denomina de poder simbólico. Com efeito, como coloca o referido autor (Bourdieu, 2003. p. 8-9), o poder simbólico seria esse poder invisivel, o qual só pode ser exercido com a cumplicidade daqueles que não querem saber que lhe estão sujeitos ou mesmo que o exercem.

Assim, se por um lado, dentro da tradição neo-kantiana de estudo dos sistemas simbólicos como estruturas estruturantes, temos que o sentido do mundo (ou suas condiçôes objetivas) define-se pela concordância das subjetividades estruturantes (mundo das idéias e valores sociais e/ou comumente aceitos), em que, sob ótica da tradição idealista de 
Durkheim, as formas de classificação deixam de ser universais (transcendendo ao ethos individual) e tornam-se formas sociais arbitrárias socialmente aceitas (que se produzem a partir de um grupo particular). Por outro, sob a ótica do estruturalismo, tributária a Schelling e Saussure, busca-se apreender a lógica que rege cada uma das formas simbólicas (ou representaçōes socialmente construídas) de modo que, diferentemente da tradição neokantiana, se busca isolar a estrutura imanente a cada produção simbólica.

Ou trossim, apesar de ambas as tradiçôes ambicionarem objetivos semelhan tes - qual seja, a apreensão da lógica que rege os processos de p rodução simbólica - estas, se diferenciam no foco que consideram como produtor da consciência. Ou seja, enquanto a tradição idealista privilegia a análise de como esse sistema simbólico opera (modus operandi), os estruturalistas buscam apreendê-lo a partir da forma como ele é produzido dentro das estruturas estruturadas (modus operatum). Deste modo, sob a ótica da tradição estruturalista e neokantiana de análise do processo de produçáo simbólica, temos que os sistemas simbólicos (ou conjunto de símbolos e significados sobre os quais opera um dado grupo e/ ou sociedade em função de seus condicionantes objetivos e subjetivos) só podem exercer um poder estruturante sobre os sujeitos que operam nesse mercado de trocas simbólicas na medida em que, enquanto instrumento do conhecimento, já se encontram estruturados no seio de um grupo ou sociedade em particular.

É, então, neste complexo sistema de construção e produção de sentidos que se ancoram as crenças e valores religiosos que permeiam a noção de estar representado, de sentir-se representado, de poder intervirno campo político. Ou seja, é no interior das comunidades religiosas que as percepçōes acerca dos escritos canônicos são muito mais presentes enquanto estruturas estruturantes do modo com que seus membros agem e operam cotidianamente (modus operandi), ao mesmo tempo em que, são por esta produzidos (modus operatum). Dito de outra forma, o que se observa é que, fora do campo religioso, os preceitos são outros e estão muito mais ligados a ética da convicção e responsabilidade do que aos valores e crenças compartilhadas por aqueles que compõem os diversos sistemas de produção simbólica ligado às comunidade religiosas. Nas palavras de Emile Durkheim teríamos então que os símbolos são, por excelência, os instrumentos pelos quais se dá a integração social, uma vez que, é através deles que se produz o consenso acerca do mundo social, permitindo assim a reprodução da ordem social - qual seja, aquela ligada ao sistema de produção simbólica constituído no interior de determinados grupos e/ou comunidades.

Neste sentido, torna-se pertinente explorarmos a noção de comunidade fornecida por Zygmunt Bauman na medida em que, para além do entendimento da noção de campo de Bourdieu, esta, nos permite entender o microcosmo que compóem cada comunidade religiosa e as formas como estas se estruturam em torno de determinadas crenças e valores ligados aos mais diversos cânones religiosos.

\section{A NOÇÃO DE COMUNIDADE EM ZYGMUNT BAUMAN}

Dentre os muitos significados atribuídos à palavra comunidade observa-se que, uma das muitas sensaçôes que essa pode nos trazer, junto com o sentimento de pertencimento, 
é o fato de "ser uma coisa boa" e, por isso, é sempre bom "estarmos nu ma comunidade". Por extensão, como coloca Bauman, se em algum momento, alguém se afasta daquilo que consideramos o caminho certo, logo, sua conduta se torna reprovável e dizemos que ela anda em má companhia. Da mesma forma se as companhias e a sociedade podem ser más, mas, a comunidade não o é.

A primeira vista, tal noção apresentada por Bauman pode nos parecer ambígua e paradoxal, uma vez que, tais sujeitos que compõem a comunidade, também, compôem a sociedade como um todo. Todavia, do ponto de vista antropológico, tal noção agrega sobre si um processo de construção de identidade e pertencimento e, fornece àqueles que a buscam, a sensação de abrigo e segurança. Nas palavras de Bauman (2003, p. 7/8)

a comunidade é um lugar "cálido", um lugar confortável e aconchegan te. É como um teto sob o qual nos abrigamos da chuva pesada, como uma lareira diante da qual esquentamos as mãos num dia gelado. Lá fora, na rua, toda sorte de perigo está à espreita; temos que estar alertas quando saímos, prestar a atenção com quem falamos e a quem nos fala, estar de prontidão a cada minuto. Aqui, na comunidade, podemos relax ar - estamos seguros, não há perigos ocultos em cantos escuros [...]. Numa comunidade, todos nos entendemos bem, podemos confiar no que ouvimos, estamos seguros a maior parte do tempo e raramente ficamos desconcertados ou somos surpreendidos. Nunca somos estranhos entre nós. [...] Se dermos um mau passo, ainda podemos nos confessar, dar explicaçōes e pedir desculpas, arrepender-nos se necessário; as pessoas ouvirão com simpatia e nos perdoarão, de modo que, ninguém fique ressentido para sempre.

Da mesma forma, diante do exposto, a comunidadeque imaginamos ser a melhor para nós, se constrói a partir daquilo que não temos em nossa "dura realidade". E, para que possamos participar dessa comunidade idealizada e desfrutar do aconchego dos seus, tornáse necessária a lealdade condicional, de modo que, ficar aquém de tal lealdade é tido como um ato imperdoável de traição para com os seus. No plano ideal, o preço a se pagar por uma "vida em comunidade" parece pequeno, mas com o tempo, pode tornar-se um ambiente abafado e opressivo. No plano dos sistemas simbólicos o tipo de entendimento que a comunidade se baseia precede a todos os acordos e desacordos, estando lá, dado, como um modus operandia sers eguido - torn ando-se um sentimento recíproco e vinculante do modus operatum de seus membros. Outrossim, por ser evidente e natural, esse entendimento compartilhado do mundo passa, muitas vezes, desapercebido àqueles que compõem a comunidade.

Do ponto de vista formal são três os elementos que Bauman, apoiado em Redfield e Tonnies, considera fundamental para a manutenção da idéia de comunidade em um plano idealizado, são eles: a sua natureza distinta (em relação a outros grupos humanos), a sua pequena amplitude (pequenez em relação ao todo social) e a capacidade de ser auto-suficiente às necessidades das pessoas que dela fazem parte.

Deste modo, estar em comunidade significa, em primeiro lugar, a necessidade de se estabelecer uma distinção en tre "quem está dentro" e "quem está fora" não permitindo a existência de "estados in termediários", que permitam ambivalên cias comportamentais. Em segundo lugar, que entre seus membros exista uma comunicação densa que coloque em

Debates do NER, Porto Alegre, Ano 7, N. 10, P. 51-64, jul./Dez. 2006 
desvantagem os "ruídos exteriores" que penetrem em seus domínios, tornando-os raros, superficiais e transitórios. E, em terceiro lugar e em decorrência do primeiro, do fato de diferenciação estabelecida entre os que pertencem ou não à comunidade, a torna autosuficiente, isolando-a quase por completo das pertu rbações dos "de fora", de modo que, a ruptura com o modus operandi da comunidade praticamente inexiste em vista da ausência de ameaças significativas ao sistema simbólico em questão. Enfim, num mundo de incertezas, a idéia de comunidade se torna atraente a homens e mulheres que buscam um porto seguro, um grupo a que possam pertencer e lhes dê a sensação de conforto e segurança.

Tal processo pode ser observado cotidianamente nas formaçôes discursivas operadas no campo religioso e político que a toda hora, no interior das comunidades religiosas promovem o (des)encantamento do mundo através de discursos que transcendem o ethos individual e buscam, ora intervir no real de forma imediata (dimensão imanente), ora não intervir e deixar a cargo da vontade divina (dimensão transcendente).

Neste momento, com base nos subsídios oferecidos por Bauman e Bourdieu no que tange à noção de campo e comunidade, podemos buscar na formação discursiva dos membros pertencentes às mais diversas congregaçôes religiosas, elementos que nos permitam entender a percepção destes sobre o campo político, de modo que possamos avaliar se há ou não, um esgotamento dos modelos explicativos, em especial, da tese do xamanismo que coloca a candidatura de Lula para além da noção de pertencimento ao Partido dos Trabalhadores e não permite que sua imagem seja maculada por esquemas de corrupção envolvendo seus correligionários políticos e/ou pessoas muito próximas ao Presidente.

\section{AS COMUNIDADES RELIGIOSAS}

\section{E SUAS REPRESENTAÇÕES ACERCA DO CAMPO POLÍTICO}

Com base em dados parciais de pesquisa realizada pelo Núcleo de Estudos sobre Religião (NER/UFRGS) no que tange a separação existente entre o campo político e religioso, temos que o religioso está muito mais associado à resolução de problemas da comunidade circunvizinha e à realização de atividades relacionadas aos grupos que pertencem, do que voltado à intervenção imediata na realidade. Da mesma forma, se delega para o âmbito do campo político problemas considerados estruturais e/ou macrossociais, em especial, observamos que pertence à esfera do político a resolução dos problemas econômicos e que os setores religiosos, na visão dos 168 respondentes, pouco ou nada podem fazer no que tange a uma solução imediata. Destaca-se, contudo, que são os evangélicos, católicos e espíritas que mais exprimem uma posição intervencionista que permeia sua ação cotidiana. Do ponto de vista prático, são os setores pertencentes às comunidades evangélicas que mostram uma maior imbricação do campo político e religioso na resolução dos problemas econômicos e sociais.

De uma maneira geral, dos 168 entrevistados até o presente momento, 73,3\% consideram a política como algo preponderante em sua vida.Tal fato denota haver, no cômputo geral, uma tendência ao estabelecimento de relaçôes desta com outras esferas da vida social, como por

Debates do NER, Porto Alegre, ANo 7, N. 10, P. 51-64, JUl./Dez. 2006 
exemplo, o campo religioso'. Da mesma forma, ao testarmos tal hipótese, em um outro conjunto de questóes solicitadas aos respondentes, a partir de um outro bloco de afirmaçóes, onde se pedia a estes delegassem a qual campo (se político, se religioso ou a ambos), competia uma tomada de atitude (ou intervenção na realidade), pudemos observar que:

1. Os problemas sociais relacionados à economia $(68,5 \%)$ e à pobreza $(51,8 \%)$ estão, para nossos respondentes, muito mais próximos da alçada política do que da alçada religiosa;

2. Em ambos os casos, o campo religioso não é dispensado de sua contribuição para a resolução de tais questões, visto que, no âmbito da população pesquisada, este pode auxiliar a política a resolver tais problemas, tanto no que se refere aos problemas econômicos $(44,6 \%)$ como aqueles relacionados à busca de uma soluçáo para a pobreza no Brasil (29,8\%).

É importante lembrar que, em outros indicadores relacionados aos problemas comumente vivenciados pela sociedade brasileira, também, houve uma associação estrita entre o campo político e religioso, com percentuais que oscilam entre 60 e 75\%. Na mesma direção, ainda destaca-se o fato de que, são os políticos oriundos do campo religioso, os que estariam menos propensos a corrupção $(35,1 \%)^{2}$.

No âmbito das especificidadesdas comunidades religiosas temosque, algumas nuanças se tornam evidentes e implicam em diferentes percepçôes e representações do campo político. Primeiramente, cabe lembrar que estamos nos referindo a um conjunto de pessoas entrevistadasque se denominam comocatólicos (106), evangélicoshistóricos(18), evangélicos pentecostais (20), espíritas (10), afro-brasileiros (7), sem religião (6) e praticantes de outras religiōes (1).

Em segundo lugar, temos que, dadas às especificidades de cada uma destas comunidades religiosas, à exceção dos católicos, há uma forte coesão nas posições assumidas e nos valores expressos pelos membros destas comunidades. Tal constatação deixa evidente, como colocado por Bauman (2003) que não há es paço para "est ados inter mediários", que permitam ambivalências comportamentais, ao mesmo tempo em que, entre seus membros há uma comunicação densa que coloca em desvan tagem os "ruídos exteriores" que penetram em seus domínios e que, no caso destas, praticamente inexistem, tornando-os raros, superficiais e transitórios. Em terceiro lugar, dada essa constatação, é passível que sejam muito pequenas as diferenças e nuanças na forma de perceber o campo político por cada uma destas comunidades, visto que, estes, consideram a religião como sendo extremamente importante em relação a outros valores sociais que como a política, também se mostram de extrema valia para o convívio em sociedade e a manutenção de "seu espaço". A tabela a seguir mostra como se dá a distribuição das respostas em relação à importância atribuída ao político e ao religioso por estas comunidades religiosas.

1 Tal afirmação assenta-se na constatação de que, comparativamente, a importância atribuída ao campo político está deveras próxima àquela atribuída ao campo religioso $(82,7 \%)$.

${ }^{2}$ Contudo como podemos observar no texto de Marcelo Tadvald nesta mesma revista, com relação aos evangélicos, nessas eleiçôes, o quadro já se mostra bem diferente.

Debates do NER, Porto Alegre, ANo 7, N. 10, p. 51-64, jul./Dez. 2006 
Tabela 1 - Importância atribuída ao político e ao religioso:

\begin{tabular}{|c|c|c|c|c|}
\hline & \multicolumn{2}{|c|}{ Religião (\%) } & \multicolumn{2}{c|}{ Política (\%) } \\
\hline & É importante & $\begin{array}{c}\text { É pouco ou } \\
\text { nada importante }\end{array}$ & É importante & $\begin{array}{c}\text { É pouco ou } \\
\text { nada importante }\end{array}$ \\
\hline Católicos & 77,3 & 21,7 & 72,7 & 25,5 \\
\hline $\begin{array}{c}\text { Evangélicos } \\
\text { Históricos }\end{array}$ & 100,0 & - & 77,8 & 22,2 \\
\hline $\begin{array}{c}\text { Evangélicos } \\
\text { Pentecostais }\end{array}$ & 100,0 & - & 70,0 & 30,0 \\
\hline Espíritas & 100,0 & - & 90,0 & 10,0 \\
\hline Afro & 100,0 & - & 42,9 & 47,2 \\
\hline Sem Religião & 16,7 & 83,3 & 83,3 & 16,7 \\
\hline
\end{tabular}

Fonte: Pesquisa NER $2006(\mathrm{n}=168)$

No que se refere aos problemas de ordem social, destaca-se que, são os evangélicos pentecostais (com percentuais que oscilam entre 75 e 85\%) e históricos (com percentuais que oscilam entre 50 e $94 \%$ ) os que consideram que a política e a religião se mostram mais imbricadas e que, juntas, podem trabalhar em prol de uma sociedade melhor. Do mesmo modo, se há certa similitude entre os evangélicos pentecostais e históricos na sua forma de perceber esses dois campos é, entre os pentecostais, que essa relação se mostra mais próxima e coesa. Sobremaneira, temos ainda que, de um modo geral, entre os membros de outras comunidades, essa relação é mais dispersa e distanciada, com especial destaque aos católicos que consideram a política como sendo o lócus privilegiado para o desenvolvimento de ações que permitam a construção de uma sociedade mais justa e igualitária (com percentuais que oscilam entre 22 e $81 \%$ ).

Diante do observado e das imbricaçóes, já constatadas por muitos autores, entre o campo político e religioso, é de se esperar que os valores sociais presentes no campo religioso e no interior destas comunidades religiosas, tais como a moral e a ética, estejam presentes em maior grau quanto maior for a coesão de posições em seu grupo e que, em virtude disto, comportamentos ambivalentes ou destoantes da comunidade (modus operandi) sejam passíveis de condenação ou recusa por parte dos membros que a compõem (modus operatum). Deste modo, no que se refere à propensão para a corrupção, estes, expressam a crença de que aqueles provindos de setores religiosos estariam menos propensos a ela, em especial, fazemos destaque aos evangélicos históricos e pentecostais, cujos percentuais totalizam mais de $60 \%$ das respostas dadas a questão.

No que se refere à percepção destas comunidades sobre o campo político e a participação cada vez maior de pastores, pais-de-santo e padres na política partidária, temos que, esta, é vista pelos católicos como uma atividade que é desenvolvida fora de sua área de atuação e que, muitas vezes, é utilizada por estes (pastores, pais-de-santo e padres) em beneficio próprio e voltada à satisfação de interesses pessoais sendo caracterizada, sobretudo, com de caráter oportunista por parte destes. Tal percepção implica em que a participação 
dos setores religiosos no campo político seja vista com desconfiança e esteja muitas vezes associada à corrupção e à manipulação das pessoas que compõem as comunidades religiosas das quais fazem parte. Outrossim, são poucos os católicos que vêem a participação de pastores, pais-de-santo e padres como um direito constitucional garantido, uma vez que, para a maioria dos entrevistados, sua participação não fará a diferença ou é vista como negativa, devido ao des preparo destes líderes religiosos para a a tuação nesse campo - o político - considerado tão diverso da religião pelos católicos.

Já no que se refere à construção imagética presente entre os católicos, no que tange a sua percepção sobre o campo político e aos políticos nele atuantes, temos que, esta é fortemente associada a imagens negativas, sendo poucos aqueles que consideram a existência (ou a atuação) dos políticos como importante para a democracia e o exercício da cidadania. De um modo geral, o político é visto pelos católicos como um indivíduo corrupto, ladrão, interesseiro, aproveitador, clientelista, desonesto, malandro, injusto, mentiroso, frio e mal-intencionado que não têm nenhum interesse pelo povo e só inspira descrença e dúvida em relação ao campo político ${ }^{3}$.

Se por um lado, entre os evangélicos históricos, o que se observa é que as duas coisas (política e religião) não devem se misturar. Por outro, se for para o bem-estar comum da sociedade é bem vista participação de líderes religiosos na política. Todavia, é preciso que, sob a ótica dos evangélicos históricos, haja uma separação entre estes dois campos, em especial, daqueles que atuam em ambas as esferas. No que se refere à imagem que estes possuem em relação aos indivíduos que atuam na política temos que, estes, são vistos como importantes para o desenvolvimento da democracia e a defesa de interesses de grupos específicos, contudo, há muitos corruptos e mentirosos nesse meio, o que acaba por produzir uma imagem negativa nas pessoas em relação à política.

Já, entre os evangélicos pentecostais, constatamos que a participaçáo de pastores, pais-desanto e padres é percebida como algo normal que pode ajudar a moralizar o campo político, visto que estes são vistos como menos propensos à corrupção. No que tange à imagem que é associada ao político temos que, dentre estes, os políticos que estão na política hoje (os profissionais) são vistos como pessoas que entraram na política só para ganhar dinheiro e trabalhar em prol de interesses próprios, sendo, em sua maioria, considerados como corruptos.

Entre os espíritas, por sua vez, essa percepção de normalidade em relação à atuaçáo de líderes religiosos é percebida,contudo, é presente a preocupação de separar a atuação política da atuaçáo religiosa, pois, em muitos casos, a religiāo pode ser usada para angariar votos. No mais, quanto ao político, percebe-se que, na maioria das vezes, sua imagem está associada a pessoas desacreditadas, que se corrompem com grande facilidade, mas que não são de todo ruins.

E, por fim, no que se refere aos afro-brasileiros e aqueles sem-religião, temos que em seu conjunto, estes vêem essa participação das lideranças no campo político como algo positivo, ainda mais, quando, no caso dos afro-brasileiros, a política - e por consequiência o político - é

\footnotetext{
${ }^{3}$ É interessante lembrar aqui que, grande parte dos católicos não possuem, necessariamente,uma ligação muito intensa com a sua religião, pois, a maioria apenas se declara como tal na falta de uma real identidade religiosa, aqui no Brasil. Portanto, tal manifestação pertence muito mais ao campo das representaçôes sociais existentes no Brasil sobre o campo político.
}

Debates do NER, Porto Alegre, Ano 7, N. 10, P. 51-64, Jul./Dez. 2006 
vista como o lócus da corrupção, da mentira e da desonestidade. Enquanto que, entre aqueles que se denominaram sem religião, este último, é visto como um indivíduo detentor de um cargo público, mas que, de uma maneira geral, não espelham aqueles que os elegeram.

\section{AS ELEIÇÕES PRESIDENCIAIS DE 2006 E A BUSCA DE MODELOS EXPLICATIVOS PARA O FENÔMENO POLÍTICO}

Se, como vimos anteriormente, tanto o campo político como o religioso, são dotados de uma dinâmica única onde crenças e valores se hibridizam em um complexo sistema de representações, temos então, que a escolha do Presidente da República não poderia escapar a esse sistema simbólico que se produz a todo instante no imaginário de milhões de brasileiros. Ao mesmo tempo, ancora-se nesta assertiva, a existência de diferentes percepçôes e representações do campo político, em razão dos valores e crenças acionados por um determinado grupo de pessoas, em especial, aquelas pertencentes as comunidades religiosas. É então, em função da percepção dessas comunidades sobre o campo político que algumas categorias explicativas podem ser buscadas no que, doravante, relacionamos à formação discursiva de Lula e ao efeito perlocutório de seu discurso.

\section{Algumas IMPRESSÕES SOBRE AS ELEIÇÕES PRESIDENCIAIS DE 2006:}

\section{OU DO MOMENTO DO RE-ESTABELECIMENTO DA ORDEM}

No que se refere às eleiçoes presidenciais, temos que, durante o primeiro turno, a estratégia utilizada por Lula foi à da não-exposição, visto que, eram muitos os candidatos e qualquer "escorregão", poderia comprometer sua imagem imaaulada de mantenedor da ordem. Apesar de alguns episódios pontuais envolvendo seus assessores diretos, poucos foram os impactos causados por estes escândalos em sua imagem pública. Como já vimos, o primeiro turno se caracterizou por uma "eleiçáo morna”, onde predominou a ausência de propostas políticas por parte das diferentes candidaturas e o intenso uso da crítica ao governo como estratégia de campanha. Destacou-se também, nesse primeiro turno, a posiçáo redentorista ou salvacionista adotada por Heloisa Helena, tática essa, usada em outras eleiçőes, pelo próprio candidato Lula.

Nesta direção, em análises realizadas por alguns pesquisadores ligados ao NER e em discussōes do grupo de pesquisa, muitas foram as alusões ao Presidente Lula como um líder político que estava acima das questôes do bem e do mal. O ponto central residia em se entender os mecanismos pelos quais, o então Presidente, conseguia, apesar dos tropeços de sua equipe política, passar incólume por uma série de escândalos envolvendo políticos e membros da equipe e do partido do governo. Chegou-se assim, a partir da análise de sua formação discursiva, antes e depois de eleito, ao que podemos denominar de "Tese do Xamanis mo". Tal tese tem seus pressupostos estabelecidos a partir de uma aproximação das categorias da magia apresentadas por Mauss (1974) ao campo político e a análise das estratégias de campanha que levou Luis Inácio Lula da Silva à Presidência da República, e 
agora, serve novamente a este como um instrumento que pode lhe permitir a reeleição ao Palácio do Planalto. Assim, ao aceitarmos tal proposição, de que o campo político pode ser visto através das categorias propostas para o mundo da magia, por contigüidade buscaremos identificar nele os mesmos elementos de seu duplo.

Desta feita, reserva-se ao político, o papel de mediador que se encarregará de evocar representações/cenários entre os eleitores a fim da consecução de seu fim último. Os discursos, então, podem ser vistos como momentos em que a política acontece. De modo que, a aceitação de uma idéia ou a aprovação de uma proposta e/ou discurso no momento de sua ocorrência, tem efeito resolutivo do problema, mesmo que não realizado materialmente, mas apenas pela carga simbólica nele contida. Por excelência, consideraremos o momento ritual, a que se refere Mauss, como sendo o momento eleitoral e seu instrumento de ação o discurso do locutor para consecução de seu objetivo último - a vitória eleitoral.

Ao testarmos o alcance de tal tese no campo político, veremos que o político em si também se destaca de seu meio, por determinada característica ou luta, sendo mais legítimo que outrem para mediar à cena política. Agrega-se a isto que, na maioria das vezes, estes têm em si o dom da oratória, fundamental para a consecução do momento discursivo, onde, por excelência, o ato político ocorre. $\mathrm{O}$ momento ritual por sua vez, precisa, em sua gênese, da evocação perlocutória (efeito do discurso) para poder, em si, evocar as representaçôes presentes na cadeia de equivalências construídas pelo campo discursivo manifesto no discurso. Ou seja, as representaçóes contidas no campo.

Estas representações serão, por sua vez, acionadas continuamente pelo locutor (o político) a fim da reificação de seu poder e na busca da eficácia de seu discurso (eficácia do ato). Sua contingência será dada pela eficácia simbólica nele contida e por sua capacidade de atingir aos fins propostos. Qual seja, o de trazer a ordem ao sistema de representaçóes constituído em torno de seu poder em sua construção discursiva. No caso deste último, pela resolução do problema (ou caos manifesto) por meio da sua construção discursiva e do re-estabelecimento da ordem, mesmo que não manifesta materialmente, mas que em tese resolve o problema (do caos manifesto ou da desordem gerada por algum desequilíbrio na correlação de forças que o torna procedente enquanto processo profilático).

Tem-se, com isto, que, no caso do Presidente Lula, o que se observa é que ele não é visto como um membro da classe política como um todo e que, por isso, não têm a ele associada uma imagem negativa. Agrega-se a isto, a desvinculação construída ao longo dos últimos anos da "pessoa do Presidente" em relação ao Partido dos Trabalhadores, visto que, foram poucas as evocaçōes que Lula fez aos símbolos do Partido em seus discursos e/ou exposiçóes públicas.

Da mesma forma, ao olharmos para o segundo turno das eleições, quando Lula passa a disputar a Presidência da República com o candidato do PSDB, Geraldo Alckmin, observamos uma mudança de estratégia de campanha. E, se no primeiro turno a estratégia foi a da não-exposição, no segundo, é o confronto entre o bem (a ordem constituída) e o mal (o caos). Para isto, foram muitos os artifícios utilizados pelos dois candidatos e, também, foi intensa a busca por apoios nas comunidades religiosas ${ }^{4}$ por parte de ambos os candidatos.

No que se refere à campanha dos dois candidatos e a forma como ambos a conduzi-

${ }^{4}$ Para maiores detalhes sobre o exposto, ver o artigo de José Rogério Lopes neste mesmo número da Revista. 
ram nesse segundo turno, alguns aspectos merecem destaque, entre eles, a postura assumida tanto por um quanto por outro em relação às denúncias de corrupção, o debate político sobre os aspectos éticos que envolvem a gestão pública de recursos, o caráter de continuidade em ambas as propostas de governo, e, sobretudo, o uso de episódios pontuais envolvendo as administrações de Alckmin em São Paulo e de Lula em Brasília, com vistas a mostrar que ambos são capazes trazer (ou manter) a ordem. Em especial, faço destaque que, em nenhum momento, se falou em mudanças estruturais, mas sim, na continuidade de projetos e na manutenção dos projetos em andamento.

O que se observa com isso, é o caráter profundamente pragmático de ambos os candidatos que, ao adotarem uma postura que não provoca o caos manifesto, conseguem, através de sua formação discursiva, explorar aspectos pontuais da gestão de seu oponente, sem gerar turbulências que possam estar além do seu poder de controle. Neste sentido, enquanto Alckmin pon tuava as pectos referen tes à compra do chamado "Aerolula" e usava como mote esse ponto para falar da gestão de recursos e o incentivo à indústria nacional, Lula se usava dos episódios envolvendo o PCC em São Paulo, para fazer referência à forma como seu governo tem lidado com o crime organizado, através de constantes operações realizadas pela Polícia Federal e a forma como os programas de geração de renda (bolsaescola, bolsa-família, etc.) podem ajudar, em longo prazo, a diminuir a criminalidade.

Assim, é latente, em ambos os casos, a tentativa de construir um discurso que permita, por si só, resolver os problemas atuais enfrentados pela maioria da população (efeito perlocutório do discurso), mas também, de estes, a todo tempo, evocarem cenários políticos que lhes permitam mostrar a sua capacidade de resoluçáo de problemas (ou de mantenimento da ordem). Não menos importante, também, é o fato de que, dada a representação que grande parte da população possui sobre a classe política, que estes pouco ou nada façam referência a suas matizes partidárias. Todavia, é interessante lembrar, como nos referimos anteriormente que, dado esse contexto de apatia política no qual nos encontramos e de uma "eleição morna", caracterizada por uma ausência de um debate político de propostas, é compreensível que, tais posturas que transcendem o debate político e buscam referência em outras esferas da sociedade, sejam manifestas com maior intensidade.

E por fim que, independentemente dos resultados da eleição do dia 29 de outubro, o que temos pela frente é um cenário político caracterizado por um desencantamento do político e uma retomada da ética e da moral a partir do campo religioso ${ }^{5}$, o qual se mostra, cada vez mais, presente no momento eleitoral, com o lançamento de candidatos ligados às mais diferentes denominaçôes religiosas ${ }^{6}$ e à busca por parte de candidatos laicos, por apoio nestes setores da sociedade. Neste sentido, também, se mostrou válida, no caso das duas candidaturas à Presidência da República, neste segundo turno das eleições de 2006, a tese do xamanismo e o uso do efeito perlocutório do discurso, como uma forma de manutenção/re-estabelecimento da ordem.

${ }^{5}$ Ver artigo de José Rogério Lopes neste mesmo número da Revista.

${ }^{6}$ Emespecial, façoreferênciaaos artigos deAriPedro Oro sobre aseleiçōes2006no RS; deRosileneSchoenfelder e Joice Paz sobre as candidaturas de pastores ligados a Igreja do Evangelho Quadrangular; e, ao levantamento feito por Marcelo Tadvald em seu texto sobre as bancadas religiosas no Congresso Nacional. 


\section{REFERÊNCIAS}

BAQUERO, Marcello. Partidos e Cultura Política na América Latina: Uma combinação de estabilidade Política? In: Baquero, Marcello (Org.). Desafios da democratização na América Latina: Debates sobre Cultura Política. Porto Alegre: Ed. da UFRGS, 1999. p. 15-30.

BARREIRA, Irlys Alencar Firmo. Chuva de papéis. ritos e símbolos de campanhas eleitorais no Brasil. Rio de Janeiro: Relume Dumará, 1998.

BAUMAN, Zygmunt. Comunidade a busca da por segurança no mundo atual. Rio de Janeiro: Ed. Zahar, 2003.

BOURDIEU, Pierre. O poder simbólico. Rio de Janeiro: Bertrand Brasil, 2003.

DA MATTA, Roberto. O ofício de etnólogo, ou, como ter anthropological blues. In: Boletim do Museu Nacional. Rio de Janeiro, n. 27, maio de 1978. p. 1-12

DAHL, Robert A. Poliarquia. São Paulo: Edusp, 1987.

FOUCAULT, Michel. Microfísica do Poder. Rio de Janeiro: Graal, 1985.

GEERTZ, Clifford. "Uma descrição densa: por uma teoria in terpretativa da cultura" e um jogo absorvente: Notas sobre a briga de galos balinesa. In: GEERTZ, Clifford. A interpretação das culturas. Rio de Janeiro: Ed. Zahar, 1978. p. 278-321.

GUIGOU, L. Nicolas. Uma relação difícil: A trama da religião em tempos de política. In: Debates do NER, Porto Alegre, ano 5, número 6, 2004, p. 171-179.

HOBBES, Thomas. Leviatã: ou, matéria, forma e poder de um estado eclesiástico e civil. São Paulo: Martin Claret, 2004.

LOCKE, John. Dois tratados sobre o governo. São Paulo: Martins Fontes, 1998.

MAQUIAVEL. O principe. São Paulo: Escala, 2005.

MAUSS, Marcel. Sociologia e Antropologia. São Paulo: E.P.U., 1974.

MEIRELLES, Mauro \& DI FRANCO, Aline. O Político e o Religioso nas eleições municipais de 2004 em Porto Alegre: Ou a metáfora do GRE-NAL. In: Debates do NER. Porto Alegre, Ano 6, n. 7, 2005, p. 99-107.

ORO, Ari Pedro. Religiōes e Eleições em Porto Alegre: Um comparativo entre 2000 e 2004. In: Debates do NER, Porto Alegre, ano 5, número 6, 2004 , p. 9-34.

ROUSSEAU, Jean-Jacques. Do contrato social; Ensaio sobre a origem das linguas; Discurso sobre a origem e os fundamentos da desigualdade entre os homens. São Paulo: Nova Cultural, 1991.

VELHO, Gilberto. Observando o familiar. In: Nunes, Edson de Oliveira (Org.). A aventura sociológica. Rio de Janeiro: Ed. Zahar, 1978. p. 36-46

\section{REFERÊNCIAS E TEXTOS CONSULTADOS NA WEB}

MOREIRA, Carlos André. Os riscos do cansaço da democracia. Disponível em : <http:/ /www.clicrbs.com.br/jorna is/zero hora/jsp/defa ult2.js p?source=Busca,a1270016.x ml\& section=Cultura $>$ Acesso em: 02 de setembro de 2006. 